\title{
Red Dot Identification System for Mithuru Piyasa to Resolve Social Problems with Medicolegal Significance
}

\author{
Konara Mudiyanselage Tikiri Bandara Gunathilake ${ }^{1 *} \triangle\left(D\right.$, Muditha Vidanapathirana $^{2}$ \\ ${ }^{1}$ Office of the Judicial Medical Officer, Base Hospital, Awissawella, Sri Lanka \\ ${ }^{2}$ Department of Forensic Medicine, Faculty of Medical Sciences, University of Sri \\ Jayewardenepura, Sri Lanka.
}

\section{Introduction}

We developed a team at the Mithuru Piyasa and introduced a new system called "Red Dot Identification System". The main objective was to identify the causative agent or "Red dot" of the problem if available. To illustrate this brand new concept, following five cases were selected from 2328 patients who visited a Mithuru Piyasa for help in 2016.

\section{Objectives}

To assess the importance of "Red Dot Identification System" (RDIS) for Mithuru Piyasa to resolve social problems with medicolegal significance.

\section{Background history}

Case-01: Father suspected that child's sexualized behaviour could be due to the observation of acts of mother's extramarital partner. Mother identified that grandmother misused the child. "Red dot" was the grandmother. Case- 02: Mother faced frequent desertion by her partners and neglected the child. Reason for desertions was her schizophrenia following postpartum psychosis. "Red dot" was the mother. Case-03: Daughters used to sleep with mother. Father developed morbid jealousy. "Red dots" were daughters. Case-04: The reason for quarrelling was morbid jealousy of husband. Case-05: A child was produced following assaults by neighbours. The parents were about to divorce. The child had a hyperactive disorder. Red dot" was the child.

\section{Discussion}

By identifying the Red dot, Mithuru Piyasa managed to counsel, arrange treatment and solve almost all such problems. Further, it enabled to keep families together or help them to separate peacefully.

\section{Conclusions}

The proposed "RDIS" is an effective method of solving such family violence and should be expanded to other hospitals too.

Keywords: Gender-based violence, Family violence, Red dot, Counselling

Copyright: @2018 with the Medico-legal Journal of Sri Lanka.

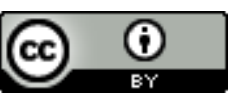

This is an open-access article distributed under the terms of the Creative Commons Attribution 4.0 International License, which permits unrestricted use, distribution and reproduction in any medium provided the original author and source are credited.

Funding: None, Competing interests: None

Received: 17 April $2018 \quad$ Accepted revised version: 01 May 2018 Published: 30 June 2018

*Corresponding author: Gunathilake KMTB, Email: tikiriii_bandara@yahoo.com ${ }^{\bigotimes}$,Tel: +94777705997

(D) https://orcid.org/0000-0002-8485-4550

Cite this article as: Gunathilake KMTB, Vidanapathirana M. Red Dot Identification System for Mithuru Piyasa to resolve social problems with medicolegal significance. Medico-Legal Journal of Sri Lanka, 2018;6(1):27-30.

DOI: http://dx.doi.org/10.4038/mljsl.v6i1.7369 


\section{Introduction}

MP is mainly a concept of the Family Health Bureau of Sri Lanka and the main objective is to help the GBV victims. The objectives of the Mithuru Piyasa (MP) was expanded to provide a better service for a wider range of victims. First, we developed a team and introduced a new system called "Red Dot Identification System" (RDIS). The main objective of the system was to realize the causative agent or "Red dot" of the Gender-based violence (GBV) if available.

According to WHO global and regional estimates (2013) regarding the magnitude of GBV in the World, "1 in 3 women throughout the world will experience physical and or sexual violence by a partner or nonpartner". ${ }^{[1]}$ The prevalence of GBV in Sri Lanka is not exceptionally low or high. According to Jayasuriya et al (2011), in ever-married women 18-49 years old in the western province, lifetime prevalence of physical violence $34.4 \%$, sexual violence $4.2 \%$ and emotional abuse $19 \% .{ }^{[2]}$ Therefore, the prevalence of GBV in Sri Lanka is on par with the average global situation. ${ }^{[3]}$

Further, it is observed that GBV contributes to committing suicides. Sri Lanka has one of the highest rates of suicides in the world. In the year 1996, there were 9000 suicide deaths and it was the highest in the world. ${ }^{[4]}$ Even in $2008-2015$, the number of suicides remained around $3000-4000$ per year. Of them, nearly 2500 were legally married. ${ }^{[5]}$ This suggests that the reasons for suicide may lie within the family such as harassment by husband, sexual incapacity, mental disorders, disappointment and frustration over love affairs, addiction to drugs and alcohol, sexual harassment and rape, ill-treatment by children and problems related to elders, and economic problems in the family. ${ }^{[5]}$

Moreover, Sri Lanka is a country with moderate alcohol consumption and according to WHO it is nearly 3.7 litres per person per year. ${ }^{[6]}$ In a study done on 116 survivors of wife battering by Vidanapathirana (2014) at Teaching Hospital, Colombo South also found that $69 \%$ of husbands consumed alcohol regularly. ${ }^{[7]}$

However, it is known that all above-mentioned conditions were not causes, but form or result of some process. To resolve the problems of the survivors of GBV, the remedies should be arranged not for the outcome but to control the reasons for committing suicide, family violence or drug addiction. Therefore, in some instances, early identification of the responsible person or the "Red dot" is very important to manage such issues and solve GBV in the family.
Therefore, it is important to have a place for the victims to complain about their problems, request for relief, to identify the problems and to obtain a reasonable answer. There are many officers who are dedicated to helping in such circumstances but are housed at different places and there is no interrelationship between these professionals to provide a better service. Most important issues in the current context are early identification of these victims, their problems and if a "Red Dot" is available, do a proper referral, initiate counselling, and if necessary start drug treatment for abuse in order to prevent further family conflicts and suicides. Therefore, it is important to have a place like Mithuru Piyasa (MP) at every hospital.

MP is mainly a concept of the Family Health Bureau of Sri Lanka and the main objective is to help the GBV victims. However, when the above facts are considered it is realized that we need to expand the objectives of MP to ensure a better and wider service to the victims and help to prevent not only intimate partner violence but also suicides, child abuse, drug abuse and to resolve some other problems also within a family. For that, the identification of the contributory factor or the "Red dot" is important, if available.

To illustrate this brand new concept of "Red dot identification system", following 5 cases were selected from 2328 who visited a Mithuru Piyasa of a provincial general hospital to seek help in 2016. It was realized that even though all of those were family problems, in some circumstances there was one person or "Red dot" who instigated all those problems.

\section{Objectives}

To assess the importance of Red Dot Identification System (RDIS) for Mithuru Piyasa to resolve social problems with medicolegal significance

\section{Few selected cases}

Case - 01

Father suspected that child's sexualized behaviour could be due to the observation of acts of mother's extra-marital partner. Mother identified that grandmother misused the child. "Red dot" was the grandmother.

\section{Case- 02}

An 8-year-old child with his mother was referred to Mithuru Piyasa. Mother faced frequent desertion by her partners and neglected the child. Reason for desertions was her schizophrenia following 
postpartum psychosis. The "Red dot" was the mother. Treatment for the mother was started and the family problems were resolved.

\section{Case-03}

Two daughters, aged 15 and 14 years used to sleep with mother. Father developed morbid jealousy. Later, mother became depressed and her libido deteriorated. Further, father became violent towards the daughters too. The "Red dot" was the daughters and the problems of the family were resolved.

\section{Case-04}

A family with four children married for four years was referred to Mithuru Piyasa by police. Husband always suspected his wife and followed her, and most of the time ended up with fights. Sometimes, he kept $10 \mathrm{~kg}$ rice bag on her head and asked her to kneel for long periods. Their relationship with neighbours and relatives was also severely disturbed and whenever any neighbour or their family member tried to develop a relationship, he suspected and tried to argue and quarrel. The "Red dot" was the husband, treatments were started and the problems of the family were resolved by requesting the parents to sleep separately.

\section{Case-05}

A child was produced following assaults by neighbours. The parents were about to divorce. The child had an attention deficit hyperactive disorder. Red dot" was child and treatments were started and the problems in the family were resolved.

\section{Discussion}

Family health bureau (FHB) of Sri Lanka has introduced the concept of Mithuru Piyasa (MP) to counsel the families of those who undergo genderbased violence (GBV). The main focus of MP is for GBV victims. In our hospital, we further expanded the services to the victims of sexual abuse, children with social, sexual and mental problems, drug abusers, attempted suicides and any person who needs counselling etc.

Once a family or a client attended Mithuru Piyasa, the first step is to allow them to talk freely and the counsellor actively listens to their stories, then it is easy to realize the main reason for family violence. Then identify, if available, the problematic person in the family or the "Red Dot". Most of the time, wife or person who admits to the hospital with suicidal attempts are not the red dot of the problem but the victim who suffered due to the activities of the red dot.
In such situation, we proposed that the main management should be based on the "Red Dot". However, we should not consider the "Red dot" as a perpetrator, but yet another victim of the same social problem of GBV.

There were few challenges. When the Red Dot was a mentally diseased person, informing and getting the red dot down for further treatments and management was a challenge. We interview both husband and wife, and counsel the normal party first and educate that the necessity of managing the affected party. We ensure to give the normal partner at least a placebo and the affected is treated with real prescribed drugs of the psychiatrist.

Another challenge was that once identified the mental illness, they are reluctant to accept treatment. With difficult patients, there is a phone line reserved to the MP and we educate the other party to inform us regarding the progress. Then a field visit and review is arranged and one of our counsellors is sent to 'red dot's home.

Successful management of a family problem is a teamwork. The team consists of, psychiatrist, police, officers in district secretariat, the judicial medical officer(JMO), hospital administrators, representatives of national child protection authority, probation officer, trained counsellors (Two counsellors are available, one is a trained nurse and the other one is a trained counsellor).

In 2016, 2328 counselling sessions were conducted and the "Red dot" were identified in 440 cases. Problems were identified and resolved in 182 cases with counselling alone. In 252 cases, psychiatric problems were identified and were referred for treatment. Three (03) cases were extreme cases and unable to stop separation by any means. In such circumstances, our strategy was allowing them to separate peacefully and then considered the future arrangements of their lives and the children. Those three (03) cases were referred to Legal Aid.

MP is kept open on Sundays. We made the environment around the MP pleasant and ensured the privacy and secrecy of the victims. Further, anybody can enter MP without any referral or notice. The psychiatry unit allocated one medical officer to deal with mental or psychiatric issues. The objective is not to find the perpetrator or fault with anyone, but to find the "Red dot" and give counselling and treatment.

The unfortunate situation we observed was the delayed presentation to the MP. Being beaten by the husband 
was accepted by $70 \%$ of the survivors of GBV in Sri Lanka and they tolerate such violence for decades. ${ }^{[8]}$ Therefore, survivors usually appear at the MP at a very late stage or end up in disasters such as committing suicide. However, MP does not label a "Red dot" as a perpetrator or make complaints to police.

\section{Conclusions}

In some circumstances, there was a "Red dot" who instigated family problems. The proposed "RDIS" is an effective method of solving such family violence and should be expanded to other hospitals too. The main objective of the system was not to label a "Red dot" as a perpetrator but to consider yet another victim of the same social problem of GBV. "RDIS" will be useful to reduce family issues such as drug abuse, alcohol abuse etc and the number of suicides following GBV.

\section{References}

1. Global and regional estimates of violence against women, prevalence and health effects of intimate partner violence and non-partner sexual violence, World Health Organization, 2013. Available from:

apps.who.int/iris/bitstream/handle/10665/85239/ 9789241564625_eng.pdf

2. Jayasuriya, V, Wijewardena, K, Axemo, P., 'Intimate Partner Violence of women in the Capital province of Sri Lanka: prevalence, risk factors and help-seeking', Violence against Women, 2011; 17(8):1086-1102.
PMID: 21890530 http://doi.org/10.1177/1077801211417151

3. Vidanapathirana M, 2nd Prof. HVJ Fernando Oration, Gender-based Violence and the Forensic Medical Practitioner. Medico-Legal Journal of Sri Lanka. 2015; 3(2): 1-8.

DOI: http://doi.org/10.4038/mljsl.v3i2.7323

4. Amaranath S. Sri Lanka suicide rate one of the world highest. World socialist web site: Available from:

https://www.wsws.org/en/articles/2012/09/srils28.html

5. Crime statistics. Sri Lanka Police. available from: www.police.lk/index/crime trends

6. Sri Lanka, World Health Organization. Available from:

www.who.int/substance_abuse/publications/glob al_alcohol_report/profiles/lka.pdf

7. Vidanapathirana M. Factors related to wife battering: a medico-legal analysis, Galle Medical Journal, 2014; 19(1): 6-10.

DOI: http://dx.doi.org/10.4038/gmj.v19i1.6958

8. Guruge S, Jayasuriya-Illesinghe V, Gunawardena $\mathrm{N}$, Perera J. Intimate partner violence in Sri Lanka: a scoping review. Ceylon Medical Journal. 2015;60(4):133-8.

DOI: http://doi.org/10.4038/cmj.v60i4.8100 